\title{
Evolução complexa de um meio-gráben: seção rifte da Bacia de Campos ba- seada em análise sismoestratigráfica
}

\author{
Patrycia ENE ${ }^{1}$, Juliano KUCHLE ${ }^{2}$, Renata ALVARENGA ${ }^{3}$, David IACOPINI ${ }^{4}$ \& Karin GOLDBERG ${ }^{5}$ \\ 1,3 Programa de Pós-graduação em Geociências, Instituto de Geociências, Universidade Federal do Rio Grande do Sul. Av. Bento \\ Gonçalves, 9500, CEP 91501-970, Porto Alegre, Rio Grande do Sul, Brasil. E-mail: patrycia.n@gmail.com, renatalvarenga@ \\ yahoo.com.br. \\ ${ }^{2}$ Departamento de Palentologia e Estratigrafia, Instituto de Geociências, Universidade Federal do Rio Grande do Sul. \\ E-mail: juliano.kuchle@ufrgs.br. \\ ${ }^{4}$ Geology and Petroleum Geology, University of Aberdeen. AB24 3UE, Aberdeen, UK. E-mail: d.iacopini@abdn.ac.uk. \\ ${ }^{5}$ Departamento de Mineralogia e Petrologia, Instituto de Geociências, Universidade Federal do Rio Grande do Sul. E-mail: karin. \\ goldberg@ufrgs.br.
}

Recebido em 28/02/2014. Aceito para publicação em 13/03/2015.

Versão online publicada em 30/04/2015 (www.pesquisasemgeociencias.ufrgs.br)

\begin{abstract}
Resumo - A seção rifte da Bacia de Campos é composta pela porção basal a intermediária do Grupo Lagoa Feia, e inclui a principal rocha geradora da bacia, e rochas reservatório carbonáticas. A interpretação e o mapeamento sistemático de linhas sísmicas 2D em uma área chave da bacia onde ocorrem dois meio-grábens, integradas com dados de perfis litológicos de poço, e a construção de uma carta cronoestratigráfica, permitiram elaborar um modelo evolutivo para a fase inicial da bacia. Assim, foram definidas dez unidades sismoestratigráficas, superfícies limítrofes chave e três sismofácies, que representam os principais grupos litológicos da seção rifte: depósitos de falha de borda, depósitos ressedimentados de grãos finos e depósitos ressedimentados de grãos grossos. A estratigrafia da Bacia de Campos foi subdividida em tratos de sistema tectônico, que refletem sua evolução tectonoestratigráfica. 0 trato de sistema de início de rifte apresenta tectônica bem distribuída. 0 trato de sistema de alta atividade tectônica é marcado pela significativa movimentação das falhas de borda; e o trato de sistemas de baixa atividade tectônica é caracterizado por um processo de fault restriction. A análise de cada etapa evolutiva levou à proposição de um modelo tectonoestratigráfico. Inicialmente os sedimentos sin-rifte foram depositados em uma depressão sinformal sem a presença de falhas de borda. Com o contínuo rifteamento e aumento da atividade tectônica, a deformação concentrou-se nas falhas principais, resultando na formação de dois meio-grábens bem estruturados com bordas de falha bem definidas. Essa fase foi seguida por uma fase de movimentação incipiente das falhas de borda até cessar o rifteamento, resultando em um preenchimento complexo e interdependente entre as diferentes calhas da bacia durante seu desenvolvimento. Palavras-chave: Bacia de Campos, sismoestratigrafia, bacia rifte, Eocretáceo, estratigrafia de sequências.
\end{abstract}

\begin{abstract}
Half-Graben Complex Evolution: the Rift Section of Campos Basin Based on SeismiC STRATigraphic ANAlysis. The rift section in the Campos Basin, comprises the basal and median portions of the Lagoa Feia Group, and includes the main source rocks in the basin, as well as carbonate reservoir rocks. Interpretation and systematic mapping of 2D seismic lines across two main half-grabens, integrated with lithological well-log data, allowed the construction of a chronostratigraphic chart and an evolutionary model for the initial phase of this basin. Ten seismic stratigraphic units, with corresponding bounding surfaces, and three seismic facies were defined, representing the main lithological groups in the rift section: border fault deposits, fine grain-dominated re-sedimented deposits and coarse grain-dominated re-sedimented deposits. The Campos Basin stratigraphy was subdivided in tectonic systems tracts, which reflect its tectonostratigraphic evolution. The rift initiation systems tract presents a well distributed tectonic. The high tectonic activity systems tract is marked by the significant fault movement. Finally, the low tectonic activity systems tract is characterized by processes of fault restriction. Analysis of each evolutionary step led to a tectonostratigraphic model. Initially, the rift sediments were deposited in synformal depression with no border fault. With continuation of the rifting process, deformation was concentrated along main faults, which led to the development of two half-grabens structure with defined border faults and increasing tectonics. This phase was followed by a stage of incipient fault movement until the cessation of rifting. Basin filling was thus complex and interdependent in the different troughs during the development of the Campos Basin.
\end{abstract}

Keywords: Campos Basin, seismic stratigraphy, rift basin, Eocretaceous, sequence stratigraphy. 


\section{Introdução}

A Bacia de Campos possui uma área de até $100.000 \mathrm{~km}^{2}$, e mais de 1.600 poços perfurados (Guardado et al., 2000). Esta bacia é de extrema importância econômica para o Brasil, pois comporta mais de $90 \%$ das reservas atuais de petróleo do país (Winter et al., 2007), excluindo as reservas do pré-sal, descobertas na última década, que compreendem a ampla área entre as bacias de Santos, Campos e Espírito Santo, aumentando consideravelmente as reservas brasileiras de hidrocarbonetos. Durante a fase rifte $( \pm 130 \mathrm{Ma})$, produziu-se um sistema de vales alongados na direção SW-NE, onde se desenvolveram horsts, grábens e meio-grábens, limitados por falhas sintéticas e antitéticas, orientados preferencialmente segundo esta direção (Dias et al., 1990).

O Grupo Lagoa Feia, depositado na fase rifte (Fig. 1), inclui rochas ricas em matéria orgânica que são as geradoras da bacia, e rochas carbonáticas, que incluem tanto os clássicos reservatórios explorados desde a década de 1970 como os recentes reservatórios do pré-sal. 0 estudo da seção rifte da Bacia de Campos ainda é limitado, principalmente devido a sua grande profundidade, que resulta em limitações tecnológicas na aquisição sísmica e na viabilidade de perfuração deste inter-

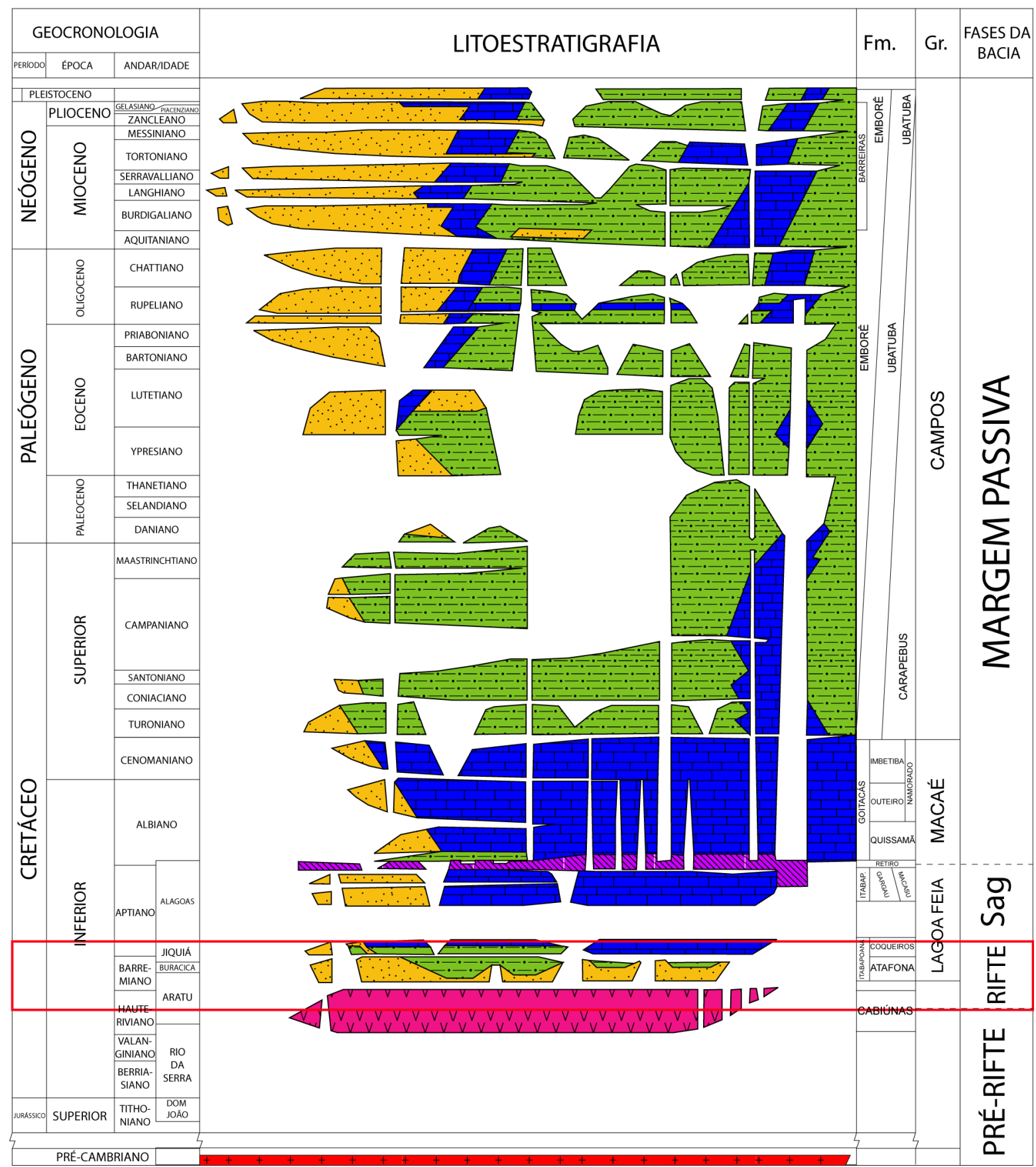

Figura 1. Carta estratigráfica simplificada da Bacia de Campos, com o intervalo de estudo em destaque no retângulo vermelho (modificado de Winter, 2007). 
valo. 0 presente trabalho visou realizar um estudo sismoestratigráfico para compreender o padrão de preenchimento de um meio-gráben, e como esse padrão foi controlado pelos fatores condicionantes da evolução de uma bacia rifte, além de estabelecer critérios de mapeamento de um arcabouço estratigráfico dentro da seção rifte da bacia.

\section{2 Área, materiais e métodos}

\section{1 Área e contexto geológico}

A margem divergente da América do Sul tem uma extensão de $10.500 \mathrm{~km}$, do delta do Orinoco, na Venezuela, até a Tierra del Fuego, no sul da Argentina (Milani \& Thomaz Filho, 2000). É uma extensa província geológica que se originou através dos mecanismos que causaram a quebra do Gondwana e resultaram na separação das placas da África e América do Sul desde o Mesozoico (Figueiredo \& Milani, 2000). O rompimento continental gerou, ainda, uma série de bacias rifte interligadas que evoluíram para um mar restrito ou proto-golfo que, com sua a abertura, evoluiu para formar uma margem passiva marinha, resultando no que é hoje o oceano Atlântico Sul (Chang et al., 1992). Durante o rifteamento, foram reconhecidos três domínios ao longo da margem continental: Domínio Atlântico Central, Domínio Atlântico Equatorial e Domínio Atlântico Sul (Milani \& Thomas Filho, 2000).

A Bacia de Campos pertence ao domínio extensional da porção sul do continente sul-americano denominado de Atlântico Sul, marcado principalmente por falhas normais dip-slip. Esse conjunto de falhas normais, que se distribui sobre este domínio, evoluiu de um padrão de rifteamento para uma margem passiva em formação. 0 processo de rifteamento e subsequente abertura do oceano Atlântico foram eventos marcantes ao longo de toda a margem da América do Sul. Com o início do fraturamento crustal no Jurássico, a margem meridional da Argentina começou a tomar forma. Esse evento se propagou até o nordeste brasileiro no Neocomiano (Milani \& Thomaz Filho, 2000). No Aptiano, as placas americana e africana estavam finalizando o processo de quebra próximo ao Equador. Desta forma, o sistema do Atlântico Sul inicia-se no Platô das Malvinas, ao sul da Argentina, e tem seu limite na plataforma de Touros, no nordeste brasileiro, compreendendo todas as bacias marginais nessa extensão. Dentro deste domínio, está situado o Platô de São Paulo, que compreende as bacias de Santos e Campos, e é delimitado pelo Alto de Florianópolis, ao sul, e pelo Alto de Vitória, ao norte (Figueiredo \& Milani, 2000; Milani \& Thomaz Filho, 2000).

A área de estudo está inserida na porção submersa da Bacia de Campos (Fig. 2), que situa-se no estado do Rio de Janeiro, Sudeste do Brasil, e possui uma área de aproximadamente $100.000 \mathrm{~km}^{2}$, onde apenas $500 \mathrm{~km}^{2}$ correspondem a sua área emersa. Ao norte, faz limite com a Bacia do Espírito Santo, sendo separada pelo Alto de Vitória, e, ao sul, com a Bacia de Santos, tendo como limite o Alto de Cabo Frio (Rangel et al., 1994). Seu embasamento cristalino corresponde ao domínio gnáissico do Pré-Cambriano presente na região. A Bacia de Campos tem sua origem associada à quebra do Gondwana, tendo início antes do rompimento e se desenvolveu como uma única bacia juntamente com as bacias de Santos e Espírito Santo (Torsvik et al., 2009), e apresenta dois estilos estruturais marcantes. Com o processo de rifteamento e deformação heterogênea, formaram-se uma série de estruturas como rampas de revezamento e hemi-grábens (a exemplo do Bloco de Santos, segundo Moulin et al., 2010). Há um padrão de falhamento de blocos, relacionado ao rifteamento inicial, e falhamentos lístricos decorrentes da tectônica salífera adiastrófica na porção superior (Guardado et al., 1990). Assim, nos estágios iniciais de abertura do oceano Atlântico, formou-se um rift valley alongado na direção SW-NE, onde se desenvolveram grábens, meio-grábens e horsts. Essas estruturas originaram altos e depocentros lacustres, onde foram depositadas as principais rochas geradoras de petróleo encontradas na Bacia de Campos, compreendidas no Grupo Lagoa Feia.

A bacia teve seu início associado ao rifteamento com intensa atividade vulcânica que resultou em um substrato vulcânico extrusivo e deu origem à Formação Cabiúnas, que apresenta idades entre 120 a $130 \mathrm{Ma}$. Seu preenchimento é dividido em três megassequências estratigráficas, associadas às fases tectônicas: megassequência rifte, megassequência transicional e megassequência marinha, correspondente à fase de margem passiva (Dias et al., 1990). O pacote rifte inclui as rochas mais antigas da bacia, pertencentes ao Neocomiano Superior-Barremiano, que fazem parte do intervalo basal a intermediário do Grupo Lagoa Feia (Winter et al., 2007), e é composto por depósitos lacustres interdigitados com rochas vulcanoclásticas da Formação Cabiúnas. A sequência transicional compreende o intervalo superior do Grupo Lagoa Feia, composto principalmente por um espesso pacote clástico basal, com intercalações de carbonatos lacustres na seção intermediária a superior (recentemente descobertos como reservatórios do 


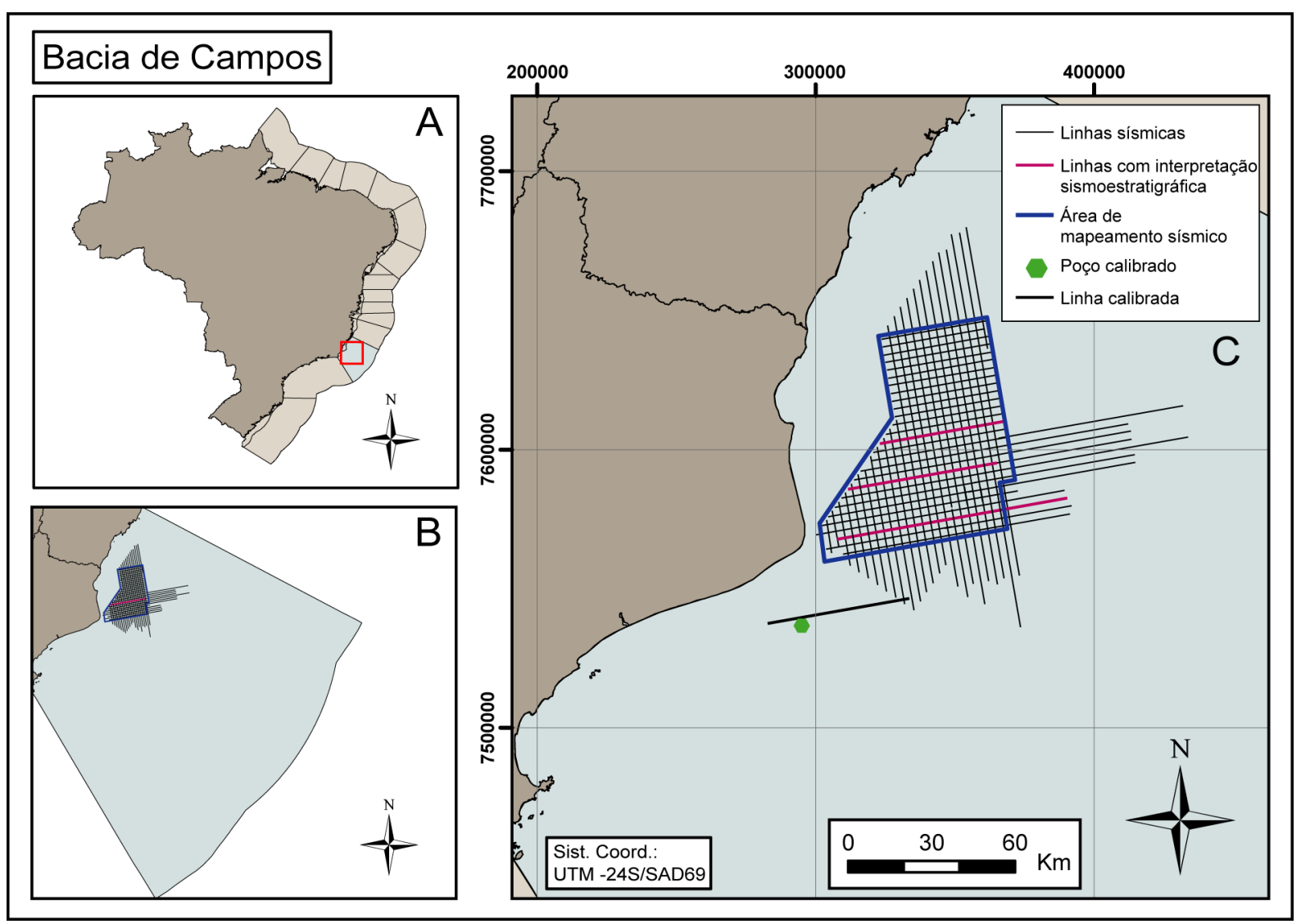

Figura 2. Mapa de localização. A) Bacia de Campos na costa brasileira; B) área de estudo em relação à área da bacia. C) Localização da área de mapeamento (polígono azul) e linhas sísmicas interpretadas. Em verde, poço calibrado junto à sísmica para a definição das sismofácies.

pré-sal), e sucedidos por evaporitos no topo. Esta sequência tem uma idade aptiana, e marca a passagem de um ambiente continental para marinho. A unidade marinha de margem passiva é composta por quatro sequências: carbonática nerítica rasa, hemipelágica, transgressiva e regressiva (Winter et al., 2007).0 Grupo Lagoa Feia constitui, em sua maioria, a seção rifte da bacia de Campos, que corresponde ao intervalo estudado no presente trabalho. Na porção basal do Grupo Lagoa Feia, estão depositados conglomerados com clastos de basalto, depósitos de fan-deltas associados às falhas de borda, arenitos finos a grossos, folhelhos ricos em matéria orgânica, siltitos e rudstones/grainstones, denominados na literatura prévia como "coquinas" (Abrahão \& Warme, 1990; Guardado et al., 1990; Rangel et al., 1994), embora não apresentem traços característicos de retrabalhamento intenso. Essas rochas caracterizam uma deposição continental, em ambiente lacustre. Os rudstones/grainstones são bioacumulados de bivalves e ostracodes com pouco retrabalhamento, que formam espessos pacotes de rochas porosas. A parte superior do Grupo Lagoa Feia é composta por sedimentos continentais grossos, com conglomerados do Aptiano e folhelhos avermelhados do Neoaptiano que gradam para evaporitos pertencentes ao mem- bro Retiro, com intercalações rítmicas de halita e anidrita (Grassi et al., 2004). As rochas dessa fase constituem a seção sag da Bacia de Campos.

A exploração de hidrocarbonetos na Bacia de Campos iniciou-se na década de 50 com a perfuração de um poço em terra. Na década de 60 foram realizados os primeiros levantamentos sísmicos, e em 1974 foi descoberto o primeiro campo de óleo da bacia (Grassi et al., 2004). As principais rochas reservatório da bacia incluem desde basaltos fraturados, rudstones/grainstones e carbonatos albianos, até turbiditos do Cretáceo e Paleógeno, sendo que as duas primeiras ocorrem na seção rifte. Os basaltos alcalinos neocomianos, intercalados com rochas sedimentares e vulcanoclásticas, formam o embasamento econômico da bacia. Esses basaltos fraturados e vesiculares estão saturados de óleo e são explorados em alguns campos da bacia, como nos campos de Badejo e Linguado (Grassi et al., 2004). Os rudstones/grainstones do Barremiano (seção sin-rifte - dentro do intervalo de estudo) são compostos de bioacumulados de conchas de bivalves e ostracodes. 0 óleo presente nesses reservatórios é de boa qualidade, os quais reservatórios são alimentados por uma rocha geradora, responsável pelo óleo e gás produzido na bacia, que consiste em um folhelho rico em estevensita, 
depositado em ambiente lacustre. A rocha geradora pode ter se formado em depressões rasas, associadas à fase inicial de distensão e rifteamento, ou durante o desenvolvimento dos meio-grábens durante a fase tafrogênica da evolução do rifte, quando lagos profundos anóxicos se formaram (Milani \& Thomaz Filho, 2000) na fase sin-rifte, caracterizando uma migração de pouca extensão. A composição química da água do lago, alcalina e rica em $\mathrm{Mg}$, contribuiu para a formação por precipitação química da estevensita encontrada em testemunhos de toda seção (Abrahão \& Warme, 1990). A janela do óleo foi atingida no Cretáceo médio, mas somente no Mioceno o pico de maturação foi alcançado. A maior parte da sequência de rochas geradoras ainda está na janela do óleo, e em apenas em alguns grábens essas rochas penetraram a janela do gás (Mello, 2006).

\subsection{Métodos}

A metodologia utilizada (Kuchle \& Scherer, 2010), específica para o mapeamento de seções rifte, foi adaptada de Vail et al. (1977), Prosser (1993) e Neal \& Abreu (2009). O mapeamento de superfícies deposicionais possibilitou a identificação de unidades sismoestratigráficas. Através da correlação entre perfis litológicos, atributos sísmicos e a análise dos refletores, foram individualizadas as sismofácies que melhor representam o conjunto de litologias do Grupo Lagoa Feia. Foram ainda construídos mapas das superfícies de base e topo do rifte, e das superfícies internas da seção rifte. São duas as superfícies internas, uma que separa o intervalo de desenvolvimento das estruturas de meio-gráben de um intervalo com maior atividade tectônica, e uma superfície que separa o intervalo com maior de outro com menor atividade tectônica, limitado pela subsequente fase sag - não analisada neste estudo. Também, foram definidos três tratos de sistemas, que segundo Brown \& Fischer (1977), trata-se de um conjunto de sistemas deposicionais contemporâneos, onde sistemas de diferentes ambientes podem simultaneamente ao longo do tempo em diferentes áreas da bacia.

Foram utilizadas linhas sísmicas 2D e perfis litológicos de poços, relacionados às seções sísmicas a partir de checkshots, obtendo assim, um controle dos dados de rocha em relação à sísmica. Em linhas dip e strike selecionadas, foi realizado o mapeamento e interpretação de refletores sísmicos para identificação das superfícies chave e estruturas encontradas na área estudada. As superfícies principais foram definidas pelas terminações dos refletores (com a identificação de onlaps, toplaps, downlaps), sendo assim possível estabelecer, além das unidades sismoestratigráficas, os tratos de sistemas (sensu Brown \& Fischer, 1977) relacionados a um controle específico (tectônico), da mesma forma que Posamentier et al. (1988) utilizaram para variações do nível relativo do mar.

Esta abordagem fornece uma metodologia sequencial de análise que pode ser aplicada em outras regiões da bacia, ou em outras bacias rifte, ou até mesmo, em outros tipos de bacias. A metodologia sequencial permite a obtenção e interpretação dos dados através do seguinte fluxograma: (1) interpretação dos refletores e suas terminações; (2) identificação das superfícies deposicionais e definição das unidades sismoestratigráficas; (3) análise e caracterização das superfícies deposicionais, definindo superfícies estratigráficas e reconhecendo eventos deposicionais ou erosivos relacionados a padrões e variáveis específicas; (4) caracterização das sismofácies, para definir os padrões relacionados aos elementos arquiteturais, sistemas deposicionais ou ambientes de sedimentação (dependendo da escala e resolução); e (5) a integração em um diagrama cronoestratigráfico, que sintetiza os eventos erosivos, os pacotes deposicionais e seus preenchimentos, bem como seus padrões de preenchimento e tendências deposicionais e variáveis controladoras.

\section{Resultados}

Mitchum et al. (1977) definem sequências deposicionais como pacotes com refletores concordantes que são separados por superfícies de descontinuidade definidas pelas terminações dos refletores (onlap, downlap, toplap, truncamento erosivo ou estrutural). Esses pacotes são compostos por estratos geneticamente relacionados e limitados no topo e na base por discordâncias ou conformidades correlativas, posteriormente definida por Posamentier et al. (1988) como um conjunto de estratos geneticamente relacionados, limitados no seu topo e base por discordâncias e conformidades correlatas, e compostas internamente por tratos de sistemas. Assim, por associação, a sequência sísmica original de Vail et al. (1977) acaba por ser equivalente aos tratos de sistemas de Posamentier et al. (1988).

As sequências sísmicas têm como superfícies limítrofes discordâncias ou conformidades correlativas. Já as unidades sísmicas, propostas por Brown \& Fischer (1977) como unidades sismoestratigráficas, são estratos cronoestratigraficamente relacionados que remetem a diferentes eventos no tempo, limitados por superfícies mapeáveis ao lon- 
go de toda a bacia e preenchidos por uma sucessão de sistemas deposicionais. As superfícies limítrofes são mapeadas com base na sua continuidade lateral, definindo um evento temporal dentro de uma unidade. É importante ressaltar que o reconhecimento desses pacotes se dá da mesma forma que uma sequência sísmica (pelas terminações de refletores), porém nem sempre as unidades sísmicas são limitadas no topo ou base por uma discordância. Suas superfícies limítrofes são apenas superfícies de controle temporal que individualizam estratos em diferentes eventos temporais. Desta forma, Brown \& Fischer (1977) utilizam o conceito de trato de sistemas, que são um conjunto de sistemas deposicionais contemporâneos, para fundamentar as unidades sismoestratigráficas, delimitadas por superfícies deposicionais ou erosivas, e que denotam períodos distintos na evolução da bacia.

\subsection{Interpretação dos refletores}

Para a análise sismoestratigráfica da área de estudo, foram interpretadas três linhas sísmicas 2D (Fig. 2) em tempo (milissegundos). A interpretação sismoestratigráfica destas três linhas forneceu o arcabouço estratigráfico geral através da delimitação de superfícies chave, que foram mapeadas em 64 linhas sísmicas 2D (29 linhas dip e 35 strike). A seleção das linhas interpretadas considera: (1) a distribuição espacial na área de estudo; (2) a qualidade do sinal sísmico; e (3) a representatividade das estruturas e padrões de reflexões para a área de estudo. A análise sismoestratigráfica consistiu em rastrear todos os refletores e suas terminações, seguindo os seguintes parâmetros: configuração dos padrões geométricos, amplitude, continuidade e frequência (Fig. 3). Como o enfoque do presente estudo é a seção rifte, foram mapeados os horizontes definidores do intervalo sin-rifte: o topo da Formação Cabiúnas como superfície basal, e a discordância de pós-rifte que separa a seção sin-rifte da seção sag da bacia como superfície de topo (Fig. 3B). Adicionalmente, foi mapeada a base do sal como superfície funcional para controle e posicionamento da seção sin-rifte. De forma geral, os horizontes do topo da Formação Cabiúnas e a discordância pós-rifte compreendem a seção sin-rifte mapeável da área de estudo, e seus significados estratigráficos serão discutidos a seguir. 0 intervalo de estudo compreende dois meio-grábens, compostos por duas falhas de borda situadas a leste de cada meio-gráben. Essas estruturas se conectam na parte superior a intermediária do intervalo de estudo, e ambas possuem vergência para leste.
Assim, os meio-grábens foram denominados como MG-01 e MG-02, respectivamente, em um corte de oeste para leste. Com a seção sin-rifte definida, foi realizada a interpretação dos refletores e terminações desta seção (Fig. 3A). Desta forma, observou-se um padrão de refletores paralelos entre si na base do rifte. Na seção intermediária do intervalo de estudo, os refletores passam a apresentar uma boa continuidade e um padrão divergente, indicando uma atividade tectônica sin-deposicional, característica da seção sin-rifte. Também se observou truncamentos estruturais, associados a pequenas falhas. 0 padrão divergente dos refletores é bastante característico de bacias rifte (Bosence, 1998), sendo definidor de uma fase sin-rifte da bacia, que é delimitada por uma discordância pré-rifte na base e uma discordância pós-rifte no topo. Por fim, acima da fase rifte ocorre a fase sag.

\subsection{Unidades sismoestratigráficas}

Os refletores e suas terminações fornecem, como determinado por Vail et al. (1977) e Mitchum et al. (1977), a caracterização sismoestratigráfica de superfícies deposicionais. Entretanto, essas superfícies deposicionais nem sempre correspondem a discordâncias, e as sucessivas terminações de refletores relacionadas e rastreáveis como uma superfície individual, não necessariamente representam hiatos deposicionais. Assim, o conceito de tratos de sistemas de Brown \& Fischer (1980) serve como base para a caracterização das unidades sismoestratigráficas. 0 rastreamento de terminações de refletores ao longo de uma superfície define o limite de base ou de topo de uma unidade sismoestratigráfica. Foram assim definidas dez unidades sismoestratigráficas (Fig. 4A), denominadas de US-1 a US-10, da base para o topo nos dois meio-grábens estudados (MG-01 e MG-02). 0 MG-01 apresenta oito dessas unidades e o MG-02, sete, sendo que quatro delas se repetem em ambos meio-grábens.

As duas primeiras unidades (US-1 e US-2) apresentam um padrão geométrico diferenciado, onde os refletores não mostram divergência em direção à falha de borda, tanto no MG-01 quanto no MG-02. Isto indica que a falha de borda já se encontrava ativa, mas em um padrão estrutural sinformal e atuando como uma falha com a mesma expressão das demais. 0 intervalo compreendido pelas US-1 e US-2, em ambos meio-grábens, retrata uma fase evolutiva sem a estruturação de meio-gráben estabelecida. Da unidade US-3 a US-7 os refletores apresentam um padrão divergente, com refletores em offlap nas porções centrais dos 
meio-grábens, alguns truncamentos estruturais e onlaps. 0 intervalo compreendido pelas unidades US-3 a US-7 marca então, uma fase de intensa atividade tectônica sin-deposicional controlada por estruturas de meio-gráben, com falhas de borda bem estabelecidas tanto no MG-01 quanto no MG-02. Adicionalmente, observa-se que os meio-grábens MG-01 e MG-02 encontravam-se isolados durante a formação das unidades US-3 a US-5. Nas unidades US-8 e US-9, os refletores são dominantemente paralelos, apresentando suaves divergências localizadas, especialmente sobre os antigos depocentros controlados pelos meio-grábens, indicando que ainda havia uma tectônica incipiente durante a deposição dessas unidades. 0 topo da unidade US-9 apresenta um truncamento erosivo e é limitada por um refletor contínuo em toda extensão da área de estudo, que separa a US-9 da US-10. Esta última corresponde à fase sag, que compreende a seção pós-rifte, caracterizada por uma atividade tectônica incipiente e regional de reajuste isostático que antecede a ruptura continental.

\subsection{Sismofácies}

A definição de sismofácies de Brown \& Fischer (1980), baseada nas publicações do Memoir 26 da AAPG de 1977 (Payton, 1977), descreve uma sismofácies como uma unidade tridimensional composta por reflexões sísmicas, cujos elementos (configuração geométrica das reflexões, amplitude, continuidade, frequência e intervalo da velocidade) diferem dos elementos das unidades adjacentes. As fácies sísmicas são interpretadas para o conhecimento da litologia, estratificação e aspectos deposicionais que geraram as reflexões dentro dessas unidades sismofaciológicas, e fornecem uma variedade de informações úteis para determinação de análogos de rochas. Essa análise é mais eficiente quando há disponibilidade de perfis de poço e testemunhos para relacionar as sismofácies dentro de um contexto litológico de uma sequência deposicional.

As sismofácies foram interpretadas com base na sua configuração, continuidade, amplitude, frequência dos refletores, velocidade intervalar e forma do conjunto de reflexões. Posteriormente as mesmas foram calibradas com os perfis compostos de uma área próxima à área de estudo, mais ao sul, onde foram descritos testemunhos em poços adjacentes e, a partir disso, definidas as associações de fácies. Assim, integrando dados de poço e sísmica (Fig. 4), foi possível relacionar a litologia dominante em cada sismofácies e propor um modelo dos processos deposicionais que preencheram esses meio-grábens durante a fase rifte da Bacia de Campos. Essa calibração proporcionou maior entendimento da relação do suprimento de sedimentos com o controle tectônico, possibilitando a criação de um modelo evolutivo dessa bacia.

Para calibração, foram analisados poços com perfis compostos que atingiram a profundidade da seção rifte e auxiliaram na compreensão o significado geológico das três sismofácies identificadas na sísmica. A figura 4 mostra como foi possível reconhecer, através dos dados de perfis compostos dos poços e de testemunhos, a natureza dos refletores e sua relação com as fácies sísmicas descritas a seguir. Fácies sísmicas não têm necessariamente um controle temporal e podem ocorrer em diferentes unidades sísmicas. Assim, foram definidas três sismofácies presentes no intervalo rifte (Fig. 5).

A sismofácies 1 apresenta uma configuração de refletores caótica, sem continuidade e com amplitude baixa a média (Fig. 6A). Sua ocorrência está geograficamente associada às falhas de borda, sugerindo que sua deposição é controlada pela movimentação das mesmas (Fig. 5B). Essa sismofácies não ocorre inicialmente, pois a falha de borda ainda não está estabelecida e não gera rejeito necessário para formar o depósito. Na parte superior do MG-01, esses depósitos não ocorrem, pois possivelmente durante os estágios finais de movimentação da falha de borda do MG-01 que já passa a se comportar como margem flexural do MG-02. Esta sismofácies é interpretada como depósitos de fan-delta, originados da erosão decorrente da elevação do bloco de footwall da falha de borda. São comumente depósitos conglomeráticos, aqui denominados de Depósitos da Falha de Borda.

A sismofácies 2 tem uma configuração divergente em sua maior parte e porções com configuração hummocky no depocentro de ambos meio-grábens. Os refletores são de baixa amplitude e variam de contínuos a descontínuos, com terminação de refletores dominantes em onlap (Fig. 6B). Da mesma forma que a sismofácies 3 , sua disposição é variada ao longo do intervalo, não existindo uma região preferencial de deposição e ocorre ao longo de toda a bacia, temporal e espacialmente, principalmente englobando os depósitos da sismofácies 3 (Fig. 5B). A sismofácies 2 é interpretada como os depósitos lacustres de background, podendo compreender também, assim como a sismofácies 3 , depósitos de fluxos gravitacionais, mas devido a sua baixa amplitude e menor continuidade lateral, são esperados depósitos mais finos em relação à sismofácies 3. Os depósitos da sismofácies 2 foram assim denominados de Depósitos de background 

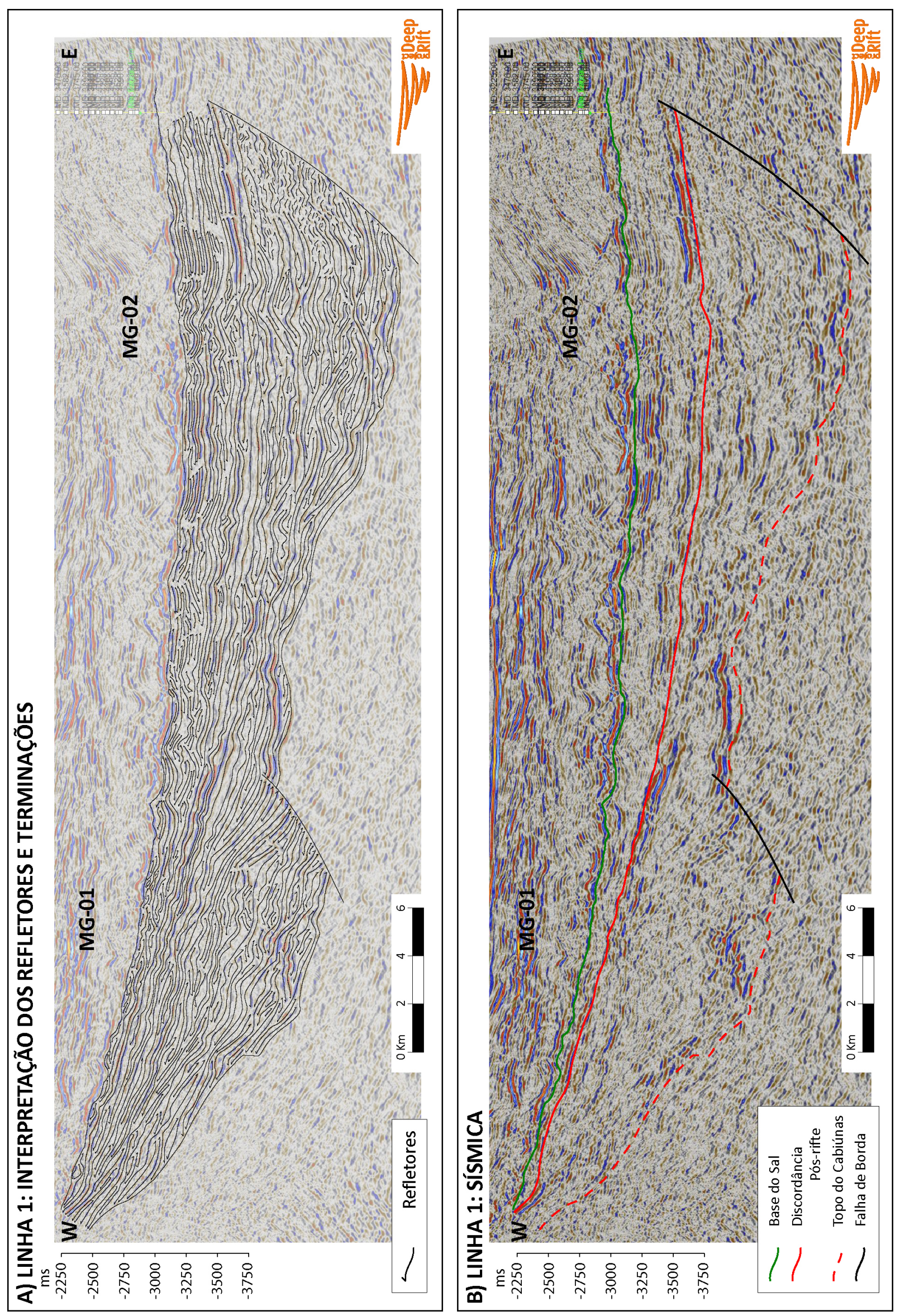

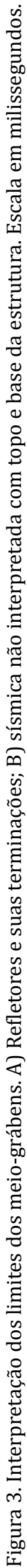


e ressedimentados dominados por grãos finos.

Na sismofácies 3, os refletores apresentam uma configuração paralela, com alta a média amplitude e boa continuidade (Fig. 6C). Predominam terminações em onlaps e alguns truncamentos estruturais cortando a sismofácies que apresenta uma geometria tabular. Esta sismofácies foi interpretada como rudstones/grainstones, que encontram-se dispostos na forma de mounds e gradações laterais para a sismofácies 2 , não sendo possível determinar tendências proximais ou distais em relação à sismofácies 2 . A sismofácies 3 está dispersa no espaço e em diversas unidades temporais distintas, podendo ocorrer tanto na margem flexural, quanto no depocentro dos meio-grábens
(Fig. 5B). Autores como Abrahão \& Warme (1990) e Rangel \& Carminatti (2000) afirmam que os depósitos de carbonatos grossos se encontram em altos estratigráficos, e considerados depósitos de margem rasa. Entretanto, a sismofácies 3 é aqui interpretada como resultado do retrabalhamento e erosão de uma margem rasa. Pulsos tectônicos resultaram no soerguimento e instabilização da plataforma carbonática, e decorrente redeposição dos sedimentos por fluxos gravitacionais. Esses depósitos foram denominados de Depósitos ressedimentados dominados por grãos grossos. Por fim, na figura 5B está representado o intervalo que corresponde à fase sag da bacia.

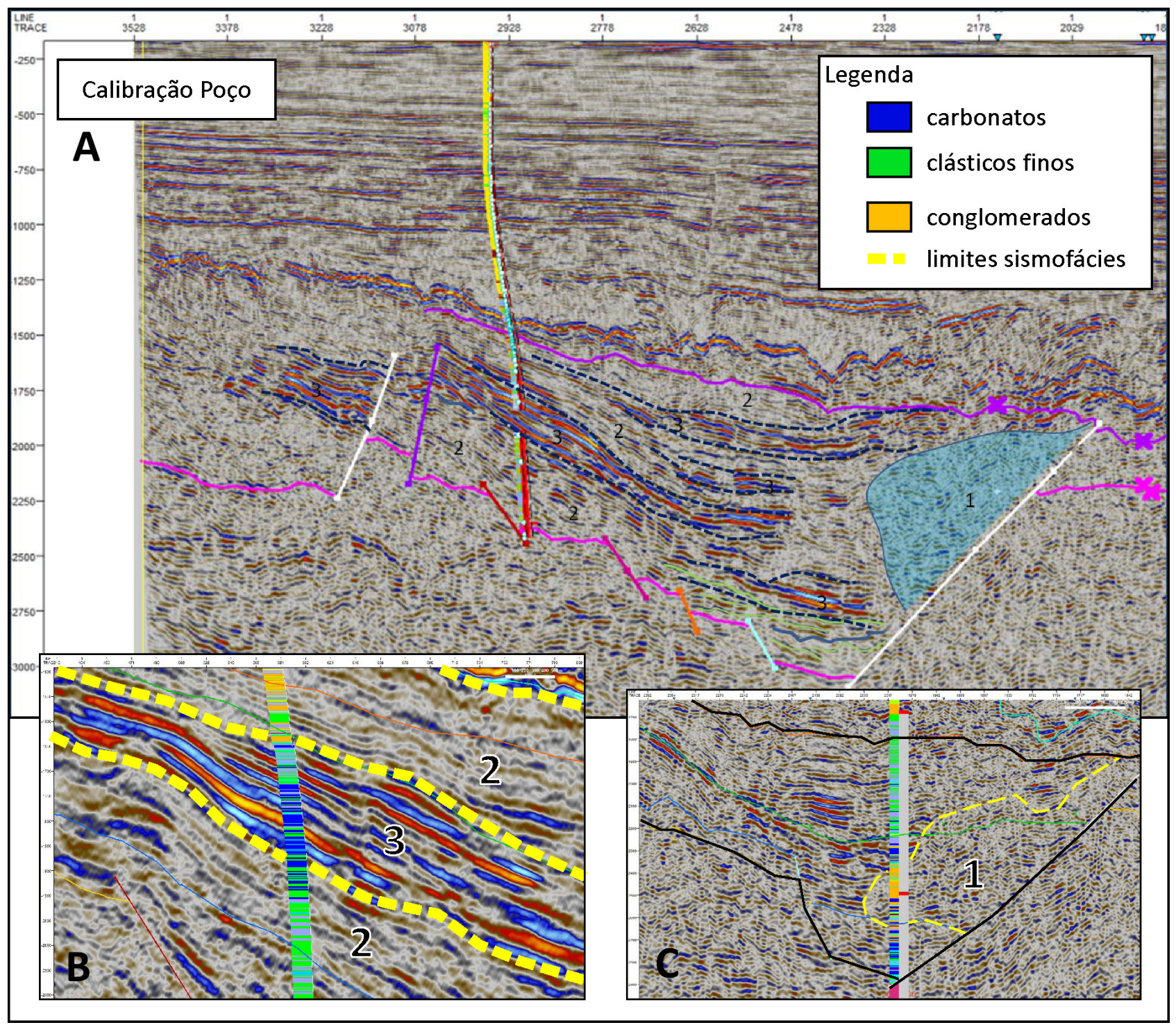

Figura 4. Calibração dos poços com a seção sísmica. A) Visão geral do poço calibrado com a sísmica; B) Sismofácies 3 representa carbonatos e sismofácies 2 representa os clásticos finos; C) Sismofácies 1 representa os conglomerados. 


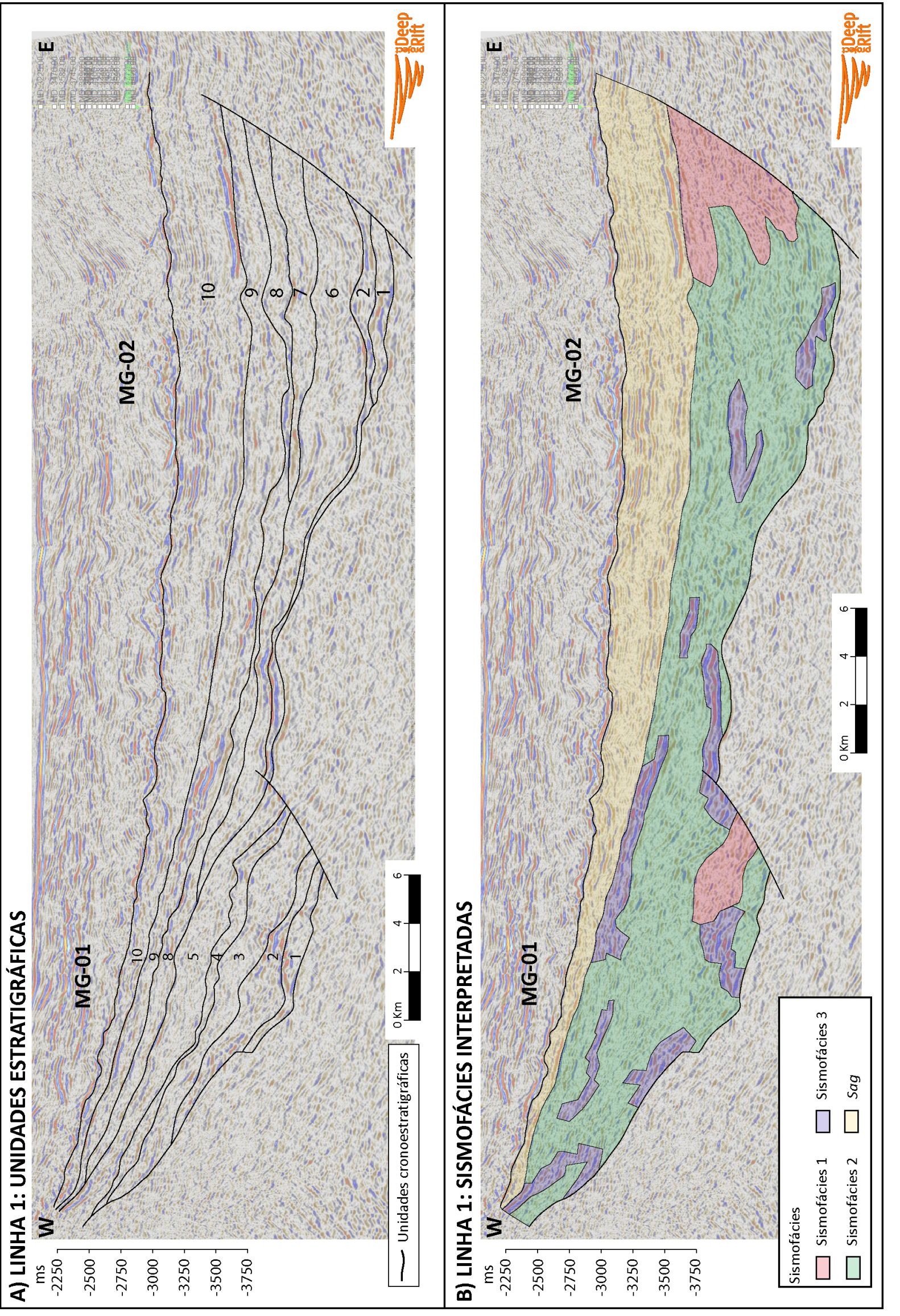

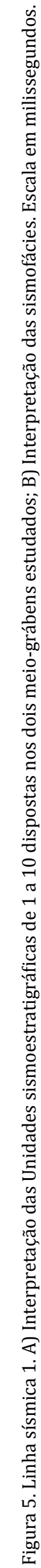




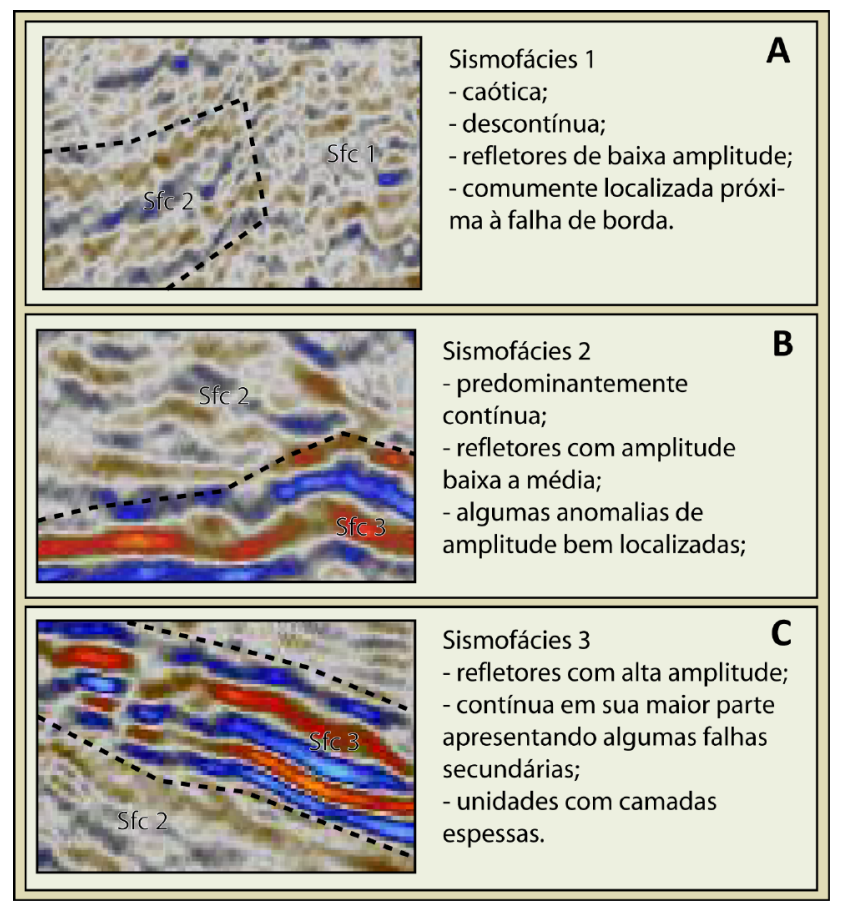

Figura 6. Características definidoras das três principais sismofácies identificadas no intervalo de estudo e suas feições. A) Simofácies 1; B) Sismofácies 2; C) Sismofácies 3.

\subsection{Carta cronoestratigráfica}

Seguindo a metodologia proposta por Vail et al. (1977), é necessário o estabelecimento de um contexto temporal para as unidades caracterizadas. Este contexto temporal remete aos fundamentos da time stratigraphy de Wheeler (1958), em que a observação de eventos deposicionais baseada em fatias de tempo permite estabelecer variações geográficas e de preenchimento ao longo do tempo geológico. Desta maneira, a elaboração de uma carta cronoestratigráfica acaba sendo fundamental para uma compreensão dos processos controladores e seus registros geológicos - as unidades sismoestratigráficas e sismofácies associadas.

A carta cronoestratigráfica mostra a evolução temporal do intervalo de estudo, do início do rifte até a porção pós-rifte (não detalhada), conforme apresentada na figura 7. Inicialmente observa-se o isolamento dos meio-grábens MG-01 e MG-02 durante as unidades US-1 e US-2. Em seguida a deposição segue no MG-01 (US-3 a US-5), enquanto esta não ocorre no MG-02. Da US-6 a US-7, não há deposição no MG-01. Durante este período a mesma ocorre de forma contínua, controlada pela falha de borda, no MG-02. Por fim, na US-8 e US-9 a área de deposição se expande, cobrindo toda a extensão da área de estudo, incluindo MG-01 e MG-02. As sismofácies 2 e 3 não apresentam um padrão deposicional específico, ocorrendo aleatoriamente ao longo do espaço e tempo de desenvolvimento da bacia. Nota-se que, enquanto o MG-01 estava em desenvolvimento, sua falha de borda não gerou grande volume de depósitos relacionados à mesma, restringindo a sismofácies 1 a US-3, ao contrário do desenvolvimento do MG-02, que teve grande contribuição dos depósitos caóticos da sismofácies 1 adjacentes a sua falha de borda. A relação entre as sismofácies 2 e 3 novamente indica um padrão aleatório de ocorrência lateral, sem relações distais ou proximais, o que sugere que a sismofácies 3 (carbonatos) é composta por depósitos ressedimentados intercalados nos sedimentos de background da sismofácies 2 , sem excluir a possibilidade de gradações para depósitos mais finos entre as sismofácies 3 e 2. No diagrama cronoestratigráfico, observa-se dois importantes hiatos que revelam a migração da atividade tectônica de um meio-gráben para outro, com o desenvolvimento de dois depocentros, que formam uma única bacia nos estágios finais da sua evolução. Isso indica que houve uma migração da atividade tectônica que controlava a falha de borda no MG-01, com uma história evolutiva única até a US-5, para a falha de borda do MG-02 na US-6. A partir desse momento, possivelmente não houve deposição no MG-01 e ocorre a deposição somente no MG-02, criando um hiato no MG-01 no período que compreende as unidades US-6 e US-7.

\section{Discussão: evolução tectônica e estratigráfica}

O modelo evolutivo tectonoestratigráfico foi baseado na distribuição espacial e temporal das unidades estratigráficas e sismofácies interpretadas. Como descrito anteriormente, nas unidades US-1 e US-2, ocorreu uma deposição isolada, sem um claro controle da falha de borda, em ambos os meio-grábens, sugerindo que a falha de borda estivesse ativa apenas como uma falha de mesma hierarquia das demais (Fig. 7). Posteriormente, nas unidades US-3 a US-5, apenas o MG-01 esteve ativo, sem deposição aparente ou visível na escala sísmica no MG-02 (Fig. 7). Já durante as US-6 e US7, o principal controle é a falha de borda do MG-02, sem aparente atividade da falha de borda do MG01 . Isso indica que a atividade tectônica migrou do MG-01 (US-3 a US-5) para o MG-02 (US-6 a US-7), fazendo com que o MG-01 virasse uma margem flexural durante as US-6 e US-7 (Fig. 7). As US-8 e US-9 apresentam um padrão deposicional muito mais amplo, ainda com controle por falhas, mas com uma expansão da área de deposição, e por fim capeadas pela US-10 (sag). 


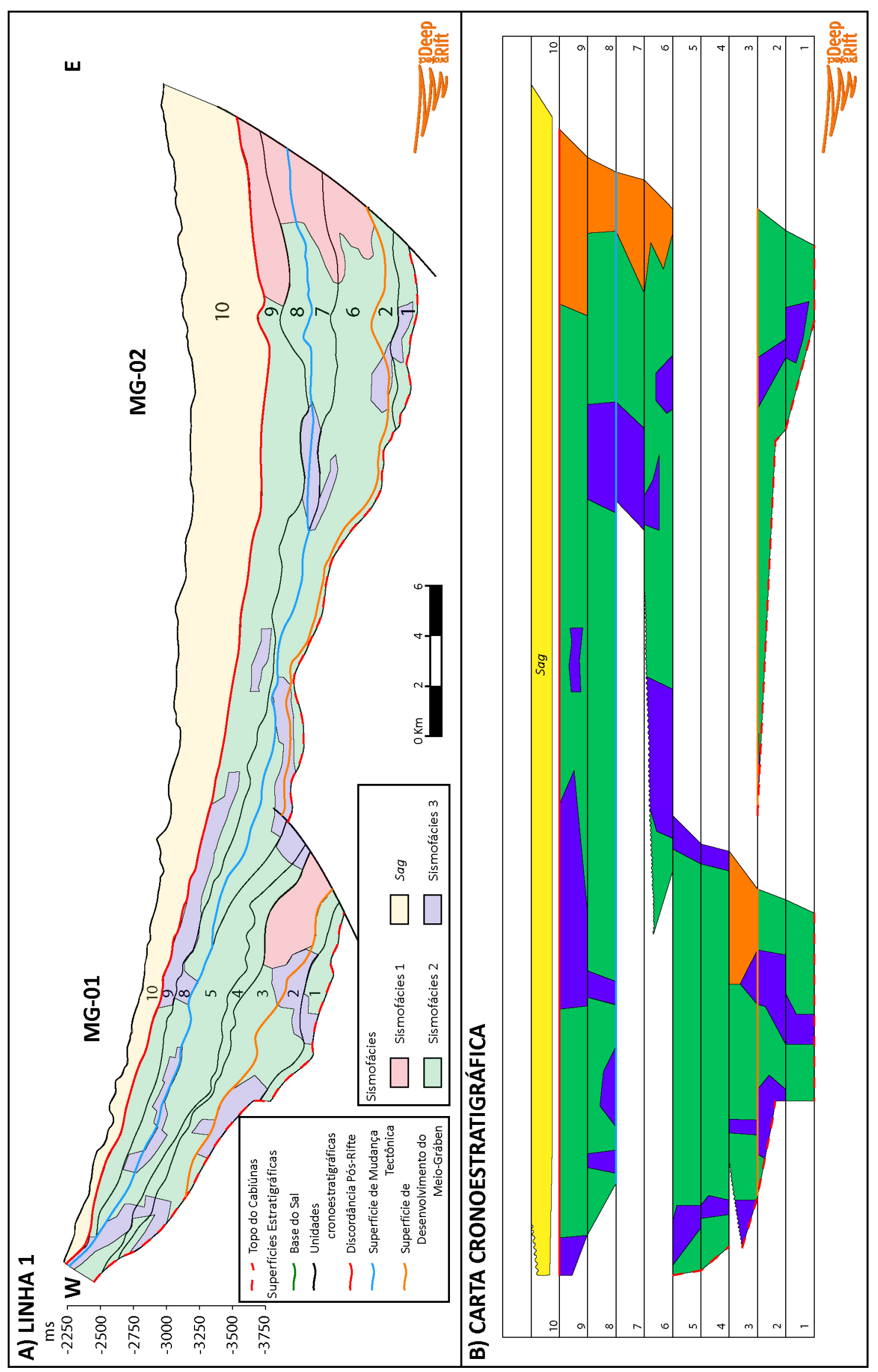

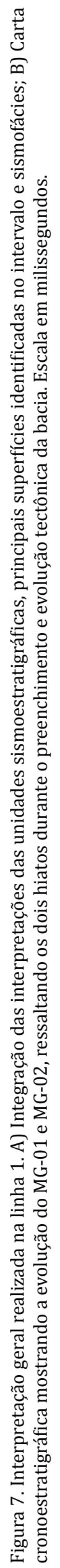


Nos estágios iniciais de abertura do rifte, que compreende as unidades estratigráficas US-1 e US-2, a movimentação de blocos ocorre simultaneamente em ambos meio-grábens. Essas unidades compreendem o Trato de Sistemas de Início de Rifte, onde a atividade tectônica é crescente e bem distribuída em toda a área de estudo (Fig. 7). Esse trato é limitado na base pela superfície denominada Topo do Cabiúnas e no topo pela Superfície de Desenvolvimento do Meio-Gráben e representa uma fase de depressão sinformal relacionada ao início do rifteamento (Morley, 2002). Esse estágio deposicional ocorre de forma síncrona na bacia, quando a sedimentação era uniforme. No mapa de isópaca sísmica (Fig. 8A), que reflete a espessura em tempo sísmico, é possível observar maior espessura nos depocentros de ambos meio-grábens. Fica visível neste trato que a deposição era bem distribuída em toda bacia e o considerável afinamento na espessura das margens flexurais indica a erosão devido ao soerguimento dessa área durante a movimentação das falhas de MG-01 e MG-02 e a exposição dos altos estruturais.

Posteriormente ocorre o Trato de Sistemas de Alta Atividade Tectônica, limitado na base pela Superfície de Desenvolvimento do Meio-Gráben e no topo pela Superfície de Mudança Tectônica. Esse estágio é marcado pela significativa movimentação das falhas de borda dos dois meio-grábens e alta geração de espaço de acomodação. 0 padrão divergente da sísmica indica a alta atividade tectônica durante essa etapa de evolução das duas estruturas, que tomam a forma de dois meio-grábens bem desenvolvidos (Fig. 7). Segundo Prosser (1993), essa transição ocorre quando a taxa de subsidência da bacia muda de relativamente baixa (sedimentação aproximadamente igual à subsidência) para alta, quando a taxa de subsidência ultrapassa a taxa de sedimentação. $\mathrm{Na}$ área de estudo, a sedimentação durante esse trato é dada por pulsos tectônicos que geram escorregamentos de sedimentos de regiões mais rasas. É dominada pelos depósitos de carbonatos grossos e finos da margem flexural erodida, e é nessa fase onde há maior representatividade das fácies de depósitos de falha de borda, comumente conglomeráticos. Ao longo da Superfície de Mudança Tectônica, truncamentos no topo apontam forte erosão da margem flexural. É durante esse trato que o MG-01 cessa a movimentação de sua falha de borda e passa a ser margem flexural do MG-02 (Fig. 7). Na isópaca do trato de alta atividade tectônica fica evidente a estruturação dos meio-grábens, e o espessamento restrito à área de acomodação gerada pela movimentação das falhas de borda (Fig. 8B), além da ocorrência de erosões nas margens flexurais (bloco de footwall), indicando a contínua movimentação na forma de rotação nos meio-grábens.

No Trato de Sistemas de Baixa Atividade Tectônica, limitado na base pela Superfície de Mudança da Atividade Tectônica e no topo pela Discordância Pós-Rifte, os refletores apresentam um padrão paralelo, sem nenhuma divergência, indicando que a movimentação da falha de borda do MG-02 foi lenta nesse estágio da evolução da bacia. Morley (2002) propôs que uma série de falhas alinhadas pode evoluir para uma única falha de borda em ambientes rifte, através do modelo de fault propagation, que nada mais é que a expansão da atividade tectônica até que essas falhas se acoplem umas às outras, formando uma única falha de borda. Núcleos de falhas menores são expandidos com o aumento da atividade tectônica, unindo pequenas bacias e gerando um grande depocentro em uma única bacia. 0 modelo de fault propagation ainda afirma que o cessamento da atividade tectônica pode ocorrer de forma abrupta ou prolongada, com lenta diminuição da atividade, que fica restrita a algumas áreas da falha de borda. Na área de estudo observa-se uma lenta diminuição da atividade tectônica no intervalo do trato de sistemas de baixa atividade, como se o modelo de fault propagation ocorresse de forma inversa, criando diferentes depocentros dentro de uma mesma bacia durante este trato. 0 mapa de isópacas dessa fase indica espessamento local em alguns pontos da bacia (Fig. 9A), diferentemente dos depocentros ao longo das falhas de borda do trato de sistemas de alta atividade tectônica. Isto sugere que nesses locais a deformação concentrou-se, com uma marcante diminuição da atividade da falha de borda, nas terminações laterais. É possível identificar pequenos depocentros ainda ativos, resultando no preenchimento final da calha (Fig. 9A). Este padrão de diminuição dos depocentros no sentido axial indica que, juntamente com a menor divergência dos estratos, a atividade tectônica era baixa, embora presente.

Após a discordância pós-rifte, inicia-se a fase sag da Bacia de Campos, na qual não foram individualizadas sismofácies, apenas identificada de forma geral para definir o intervalo de estudo. Essa fase é limitada no topo por uma superfície funcional denominada de Base do Sal, e na base pela Discordância Pós-Rifte.

No mapa de isópacas que compreende toda a fase rifte, limitada pelo Topo do Cabiúnas na base e no topo pela Discordância Pós Rifte, é possível identificar a estruturação de ambos os meio-grábens que compõe a área de estudo, podendo ser 
facilmente identificáveis a margem flexural, área menos espessa, de cada meio-gráben e seus respectivos footwalls, área mais espessa (Fig. 9B). Entretanto, embora os meio-grábens sejam evidentes no mapa de isópacas total da seção sin-rifte, o MG01 somente esteve ativo durante o período compreendido pelas US-3 a US-5, passando a servir como margem flexural para o MG-02 no período compreendido pelas US-6 a US-9.

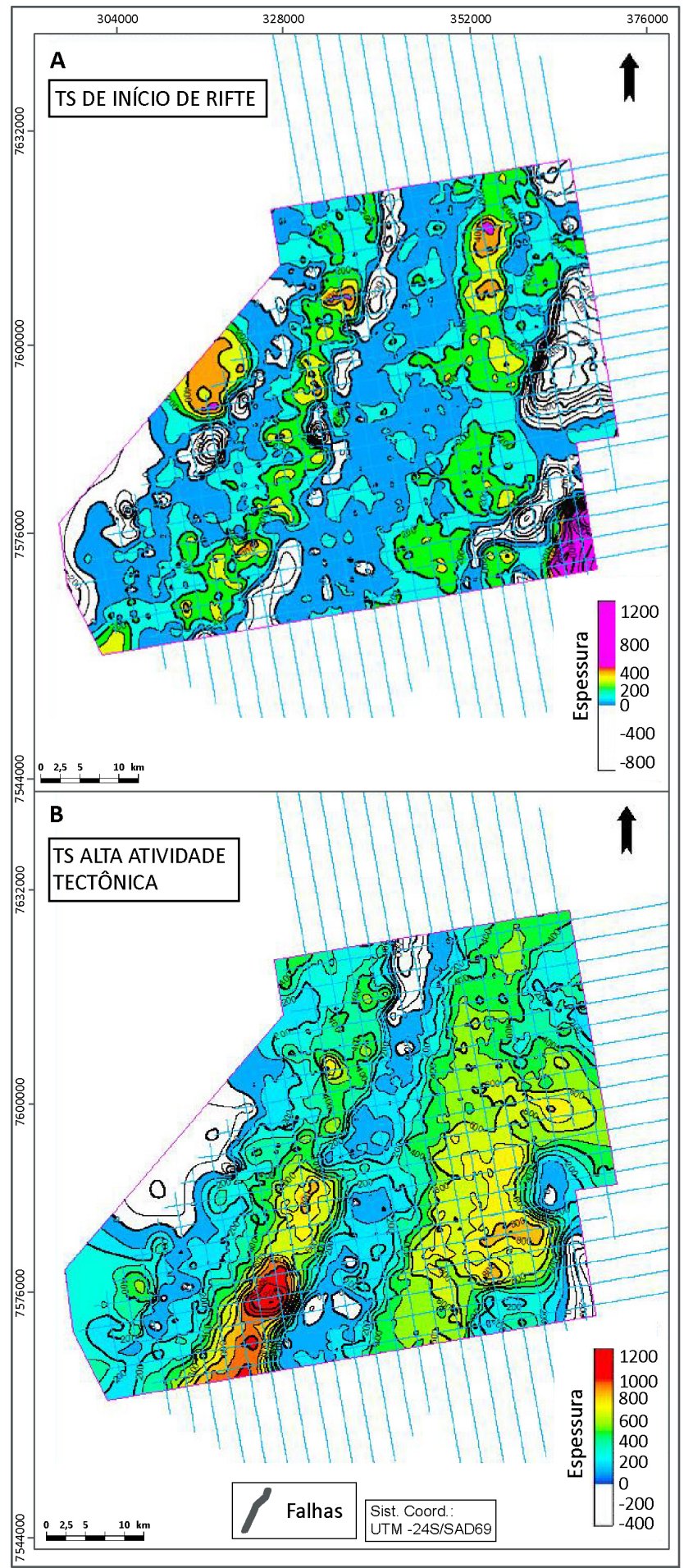

Figura 8. Mapa de isópacas mostrando a espessura em tempo sísmico (milissegundos) da evolução dos meio-grábens. A) Trato de Início de Desenvolvimento do Meio-Gráben; B) Trato de Alta Atividade Tectônica.

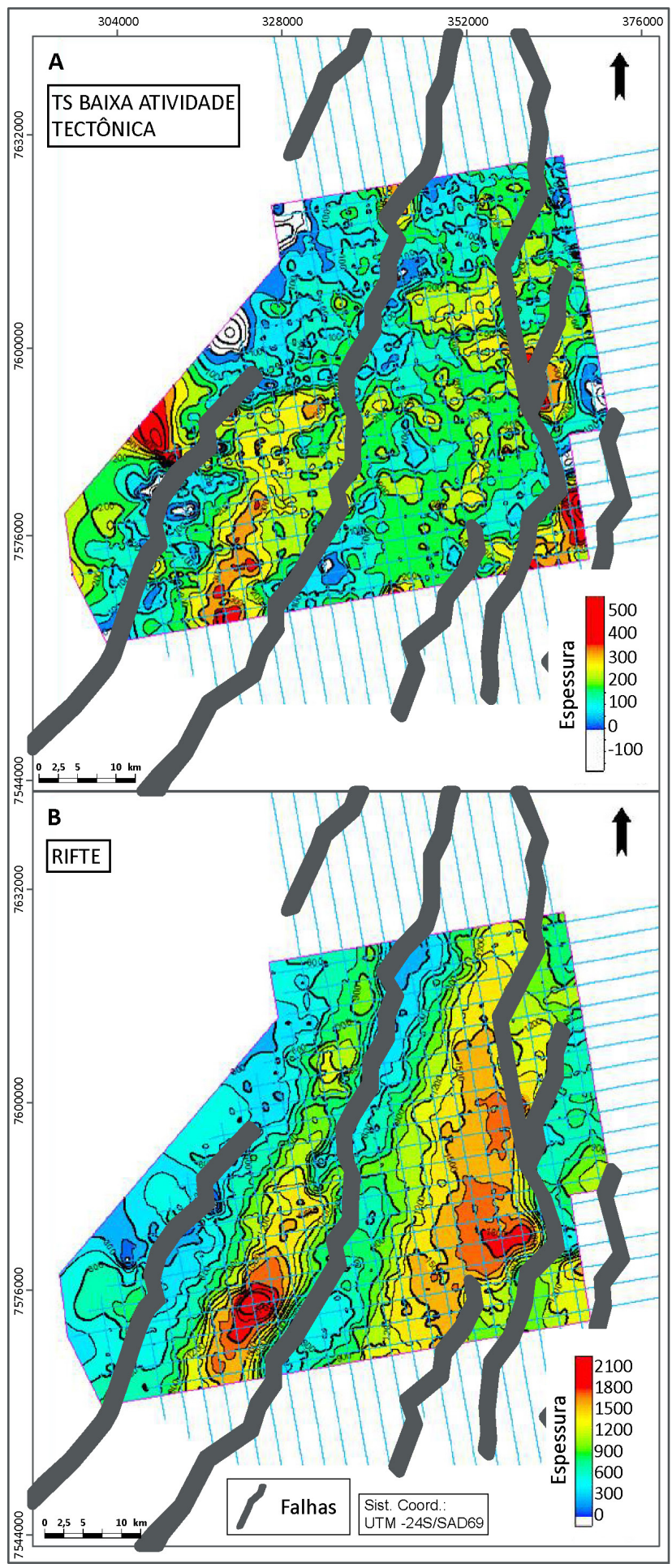

Figura 9. Mapa de isópacas mostrando a espessura em tempo sísmico (milissegundos) da evolução dos meio-grábens. A) Trato de Baixa Atividade Tectônica; B) Fase Rifte.

\section{Conclusões}

Através do mapeamento sistemático em linhas sísmicas 2D, foi possível a caracterização de refletores e definição de superfícies sísmicas, sismofácies e tratos tectônicos que abrangem toda a área de estudo. Este mapeamento sistemático permitiu compreender a evolução tectonoestratigráfi- 
ca deste intervalo rifte.

A integração da interpretação sísmica com dados de poço levou a geração de um modelo evolutivo para os meio-grábens da Bacia de Campos no intervalo rifte que engloba o Grupo Lagoa Feia. Durante sua evolução, a Bacia de Campos apresenta três importantes estágios de desenvolvimento na fase rifte: o trato de sistema de início de rifte, onde a bacia ainda é uma depressão sinformal, sem estruturas de meio-grábens desenvolvidas; o trato de sistema de alta atividade tectônica, com padrão de refletores divergentes e alta geração de espaço de acomodação; e por fim, o trato de sistemas de baixa atividade tectônica, onde ocorre uma significativa diminuição na atividade das falhas de borda, gerando deposição pontual de sedimentos ao longo da falha de borda, em um modelo de "fault restriction", inverso ao de "fault propagation" de Morley (2002). A evolução durante o trato de sistemas de alta atividade tectônica mostrou uma complexa evolução, com a migração da deformação do MG01 para o MG-02, transformando, no final, o MG-01 em uma margem flexural do MG-02. Este processo evolutivo transformou o preenchimento dos meio-grábens em um padrão extremamente complexo e de difícil caracterização, pois muito dos depósitos do MG-02 podem ser ressedimentados, oriundos da margem flexural que erode o MG-01. Desta forma, a relação entre meio-grábens, complexa e multifásica, e mesmo dentro de um trato de sistemas, leva a um padrão evolutivo peculiar, somente observável a partir da definição e caracterização das unidades sismoestratigráficas.

Agradecimentos - Este estudo constitui parte da dissertação de mestrado da primeira autora (PE) junto ao Programa de Pós-graduação em Geociências da UFRGS, integrada ao Projeto Deep Rift, desenvolvido em parceria entre a Universidade Federal do Rio Grande do Sul e a BG Brasil, amparado pela Lei do Petróleo. Agradecemos especialmente ao Global Technology Centre da BG Brasil pelo apoio financeiro e contribuições técnicas ao projeto. Adicionalmente, agradecemos à ANP pelo compromisso com investimentos em pesquisa e desenvolvimento.

\section{Referências}

Abrahão, D. \& Warme, J.E. 1990. Lacustrine and Associated Deposits in a Rifted Continental Basin - Lower Cretaceous Lagoa Feia Formation, Campos Basin, Offshore Brazil. In: Katz, B.J. (Ed.). AAPG Memoir 50 - Lacustrine Basin Exploration, Case Studies and Modern Analogs. Tulsa, American Association of Petroleum Geologists, p. 287-305.

Bosence, D.W.J. 1998. Stratigraphic and sedimentological models of rift basins. In: Purser, B. H. \& Bosence,
D.W.J (Eds.). Sedimentation and Tectonics of Rift Basins: Red Sea - Gulf of Aden. London, Chapman \& Hall, p. 9-25.

Brown Jr, L.F. \& Fischer, W.L. 1977. Seismic Interpretation of Depositional Systems: Examples from Brazilian Rift and Pull-Apart Basins. In: Payton, C.E. (Ed.). AAPG Memoir 26 - Seismic Stratigraphy - applications to hydrocarbon exploration. Tulsa, American Association of Petroleum Geologists, p. 213-248.

Brown Jr, L.F. \& Fischer, W.L. 1980. Seismic Stratigraphic Interpretation and Petroleum Exploration - Continuing Education Course Note Series \#16. Tulsa, American Association of Petroleum Geologists, 215p.

Chang, H.K., Kowsmann, R.O., Figueiredo, A.M.F. \& Bender, A. 1992. Tectonics and stratigraphy of the East Brazil Rift system: an overview. Tectonophysics, 213: 97-138.

Dias, J.L., Scarton, J.C., Guardado, L.R., Esteves, F.R. \& Carminatti, M. 1990. Aspectos da evolução tectono-sedimentar e a ocorrência de hidrocarbonetos na Bacia de Campos. In: Raja Gabaglia, G.P.\& Milani, E.J. (Eds.). Origem e Evolução de Bacias Sedimentares. Rio de Janeiro, Petrobrás, p. 333-360.

Figueiredo, A.M.F. \& Milani, E.J. 2000. Petroleum Systems of South American Basins. In: Cordani, U.G., Milani, E.J., Thomaz Filho, A. \& Campos, D.A (Eds.). Tectonic Evolution of South America. Rio de Janeiro, p. 689-718.

Grassi, A.A., Castro, A.H.A. \& Albertão, G.A. 2004. Bacias Sedimentares Brasileiras - Bacia de Campos. Informativo Phoenix, 65:1-6.

Guardado, L.R., Gamboa, L.A.P. \& Luchessi, C.F. 1990. Petroleum geology of the Campos Basin, Brazil: a model for a producing Atlantic-type basin. In: Edwards, J.D. \& Santogrossi, P.A. (Eds.). AAPG Memoir 48 - Divergent/passive margin basins. Tulsa, American Association of Petroleum Geologists, p. 3-80.

Guardado, L.R., Spadini, A.R., Brandão, J.S.L. \& Mello, M.R. 2000. Petroleum System of the Campos Basin, Brazil. In: Mello, M. R., Katz, B. J. (Eds.). AAPG Memoir 73 - Petroleum system of South Atlantic margins. Tulsa, American Association of Petroleum Geologists, p. 317-324.

Kuchle, J. \& Scherer, C.M.S. 2010. Sismoestratigrafia de bacias rifte: técnicas, métodos e sua aplicação na Bacia do Recôncavo. Boletim de Geociências da Petrobrás, 18(2): 179-206.

Mello, M.R. 2006. 3D Petroleum System Modeling and Exploration Risk Assessment of the Greater Campos Basin: go deep for giant oil and gas fields. In: RIO OIL \& GAS EXPO AND CONFERENCE, 2006, Rio de Janeiro. Anais... Rio de Janeiro, v. 1.

Milani, E.J. \& Thomaz Filho, A. 2000. Sedimentary Basins of South America. In: Cordani, U.G., Milani, E.J., Thomaz Filho, A. \& Campos, D.A (Eds.). Tectonic Evolution of South America. Rio de Janeiro, p. 389-449.

Mitchum Jr., R.M., Vail, P.R. \& Sangree, J.B. 1997. Seismic stratigraphy and global changes of sea level, part 6: stratigraphic interpretation of seismic reflection patterns in depositional sequences. In: Payton, C.E. (Ed.). AAPG Memoir 26 - Seismic Stratigraphy - appli- 
cations to hydrocarbon exploration. Tulsa, American Association of Petroleum Geologists, p. 117-133.

Morley, C.K. 2002. Evolution of large normal faults: evidence from seismic reflection data. American Association of Petroleum Geologists Bulletin, 86(6): 961978.

Moulin, M., Aslanian, D., Unternehr, P. 2010. A new starting point for the South and Equatorial Atlantic Ocean. Earth Science Reviews, 98: 1-37.

Neal, J., Abreu, V. 2009. Sequence stratigraphy hierarchy and the accommodation succession method. Geology, 37:779-782.

Payton, C.E. 1977. AAPG Memoir 26 - Seismic Stratigraphy - applications to hydrocarbon exploration. Tulsa, American Association of Petroleum Geologists, $516 \mathrm{p}$.

Posamentier, H.W., Jervey, M.T. \& Vail, P.R. 1988. Eustatic Controls on Clastic Deposition I - Conceptual Framework. In: Wilgus, C.K., Hastings, B.S., Kendall, C.G.St.C., Posamentier, H.W., Ross, C.A. \& Van Waggoner, J.C. (Eds.). SEPM Special Publication, 42 - Sea-level changes: an integrated approach. Tulsa, SEPM Strata Society for Sedimentary Geology, p. 109-124.

Prosser, S. 1993. Rift-related linked depositional systems and their seismic expression. In: Williams, G.D. \& Dobb, A. (Eds.). Geological Society Special Publication, 71 - Tectonics and Seismic Sequence Stratigraphy. London, Geological Society of London, p. 35-66.
Rangel, H.D., Martins, F.A.L., Esteves, F.R. \& Feijó, F.J. 1994. Bacia de Campos. Boletim de Geociências Petrobrás, 8(1): 203-217.

Rangel, H.D. \& Carminatti, M. 2000. Rift lake stratigraphy of the Lagoa Feia Formation, Campos Basin, Brazil. In: Gierlowski-Kordesch, E.H. \& Kelts, K.R. (Eds.). AAPG Studies in Geology 46 - Lake basins through space and time. Tulsa, American Association of Petroleum Geologists, p. 225-244.

Torsvik, T.H., Rousse, S., Labails, C., Smethurst, M.A. 2009. A new scheme for the opening of the South Atlantic Ocean and the dissection of an Aptian salt basin. Geophysical Journal Internacional, 177: 13151333.

Vail, P.R., Mitchum Jr., R.M., Todd, R.G., Widmier, J.M., Thompson III, S., Sangree, J.B., Bubb, J.N. \& Hatlelid, W.G. 1977. Seismic stratigraphy and global changes of sea level. In: Payton, C.E. (Ed.). AAPG Memoir 26 - Seismic stratigraphy - applications to hydrocarbon exploration. Tulsa, American Association of Petroleum Geologists, p. 49-212.

Wheeler, H.E. Time Stratigraphy. 1958. American Association of Petroleum Geologists Bulletin, 42: 10471063.

Winter, W.R., Jahnert, R.J. \& França, A.B. 2007. Bacia de Campos. Boletim de Geociências Petrobrás, 15(2): 511-529.

Manuscrito 538.

Editores: Iran Corrêa e Paulo A. Souza. 